\title{
The Experimental Study on Improving the Late Properties of Sulphoaluminate Cement Products
}

\author{
Hong-zhen Wang ${ }^{1}$ Fang-jie Shao ${ }^{2}$ Yan-zhi Tian ${ }^{3}$ and Liang-liang Ma ${ }^{3}$ \\ ${ }^{1}$ School of Civil Engineering, Northwest University for Nationalities, Lanzhou 730124, China \\ ${ }^{2}$ Key Laboratory of Disaster Prevention and Mitigation in Civil Engineering of Gansu \\ Province(Lanzhou University of Technology),Lanzhou 730050,China \\ ${ }^{3}$ Lanzhou Haifeng Building Material Technology Co Ltd, Lanzhou 730050,China
}

Keyword : Sulphoaluminate Cement Products, Portland Cement, Silica Fume, Late Performance

\begin{abstract}
This paper adopts rapid hardening sulphoaluminate cement compound Portland cement, silica fume and method of adding additives such as boric acid, through the experimental study of late properties of sulphoaluminate cement based composite cementitious material, the hydration product analysis and analysis of the hydration mechanism to clarify its mechanism.
\end{abstract}

\section{Introduction}

At present, sulphoaluminate cement as cementitious materials in new wall materials and building energy-saving products are widely used in construction engineering, its early strength, rapid hardening, low alkalinity and low shrinkage characteristics are significant in the production of wall material products[1]. However, the later strength shrinking and surface easy carbonation and powder caused durability problem is also very prominent, seriously affected its basic cementitious materials in cement concrete products and engineering applications. This paper adopts rapid hardening sulphoaluminate cement compound Portland cement and method of adding silica fume and boric acid additives etc., through the experimental study on the later performance of sulphoaluminate cement based on composite cementitious material, the hydration product analysis and research of the hydration mechanism to clarify its mechanism, solving the problem of durability of sulphoaluminate cement products[2].

Experimental study was carried out that the paper adopted adding Portland cement, silica fume and borax additive measures, and the improvement of the performance of cement, hydration products and mechanism are analyzed and studied.

\section{Experiment and Experiment Methods}

\section{Raw Materials}

In order to make the basic research closer to the industrial production practice, the raw materials used in the experiment are all industrial raw materials produced by the cement production enterprises. At the same time to avoid the manufacturers of cement mixed material varieties are different, deviation effect of different adding amount on non specified experimental factors caused by experimental study. Before the experiment, the rapid hardening sulphoaluminate cement and Portland cement carry out the national standard conformance test, and the proportion of amount of clinker, gypsum modifier dosage, varieties of mixture material and dosage were determined. All kinds of cement materials used in the experiment were carried out under the same non experimental factors of gypsum modifier and mixture. The test of raw materials mainly include rapid hardening sulphoaluminate cement ,ordinary Portland cement,silica fume and boric acid.

(1) Rapid hardening sulphoaluminate cement: the rapid hardening sulphoaluminate cement products in Gansu, sulphoaluminate cement is mainly composed of calcium sulphoaluminate and dicalcium silicate as the main cement of mineral composition.

(2) Ordinary Portland cement: use Qilian Mountains brand 42.5 ordinary portland cement 
produced in Gansu area. Mineral composition of two kinds of clinker (\%) as shown in table 1.

Table 1. Chemical compositions of the two cements (\%)

\begin{tabular}{c|c|c|c|c|c|c|c|c|c}
\hline Item & Loss & $\mathrm{SiO}_{3}$ & $\mathrm{Al}_{2} \mathrm{O}_{3}$ & $\mathrm{Fe}_{2} \mathrm{O}_{3}$ & $\mathrm{CaO}$ & $\mathrm{MgO}$ & $\mathrm{SO}_{3}$ & $\mathrm{TiO}_{2}$ & Total \\
\hline PC clinker & 2.74 & 19.97 & 5.09 & 4.45 & 62.97 & 2.42 & 1.55 & - & 99.19 \\
\hline CSA clinker & 0.24 & 8.24 & 34.35 & 2.02 & 41.45 & 2.54 & 8.87 & 1.48 & 99.2 \\
\hline
\end{tabular}

(3) Silica fume: the main chemical composition of silica fume is amorphous silica, Northwest iron alloy factory products, through test determination: Determination of the nitrogen adsorption specific surface area is larger than $15000 \mathrm{~m}^{2} / \mathrm{kg}$, the active index (28 days) $\geq 85 \%$. The main chemical composition and content of silica fume were determined before test.

Table 2. Main chemical composition and content of silica fume (\%)

\begin{tabular}{c|c|c|c|c|c}
\hline $\mathrm{CaO}$ & $\mathrm{SiO}_{2}$ & $\mathrm{Fe}_{2} \mathrm{O}_{3}$ & $\mathrm{Al}_{2} \mathrm{O}_{3}$ & $\mathrm{MgO}$ & Loss \\
\hline 0.34 & 91.08 & 1.34 & 0.86 & 0.27 & 3.09 \\
\hline
\end{tabular}

(4) Borax or boric acid: marketed goods, content $99.6 \%$, molecular formula: $\mathrm{H} \square \mathrm{BO} \square$, an inorganic acid, white crystalline powder or colorless microstrip pearl luster scale. Soluble in water, aqueous solution was weakly acidic.

\section{Test Preparation and Methods}

(1) Physical and mechanical tests: According to the test plan, the laboratory design different mix proportion, using the rapid hardening sulphoaluminate cement, Portland cement, silica fume mixed evenly, made of composite cementitious materials for use with small double helix cone mixer. According to the glue sand ratio 1:3, with ISO standard sand, in cement mortar mixer, according to the test mix plus boric acid and water sample preparation. Water binder ratio 0.5 in test, specimen size is $40 \mathrm{~mm} \times 40 \mathrm{~mm} \times 160 \mathrm{~mm}$, standard test conditions of conservation, respectively, $1 \mathrm{~d}$, $3 \mathrm{~d}, 7 \mathrm{~d}, 28 \mathrm{~d}$ compressive and flexural strength, $28 \mathrm{~d}$ drying shrinkage value, softening coefficient, carbonation coefficient and antifreeze index; Same specimen placed in dry indoor environment determine above index after 90d,180d, observe the powder state of the surface. Comparative analysis of relevant indicators data.

Firstly, by adding Portland cement in rapid hardening sulphoaluminate cement $(5 \%, 10 \%, 20 \%$, $25 \%, 30 \%)$ And silica fume $(5 \%, 10 \%, 15 \%)$, boric acid $(0.1 \%, 0.3 \%, 0.5 \%)$ single factor experiment. Through the analysis of single factor test and then do orthogonal test, determine the best ratio in the test conditions.

(2) Microscopic analysis test: preparation and analysis of hydration sample, the cement mortar samples with different proportioning were taken out after curing period., knocked into $2 \mathrm{~mm}$ Square Small pieces, put it in acetone solution immediately and keep it in airtight, termination of its hydration, for subsequent trial use.

XRD analyses the composition of cement hydration products:

After the aged slurry specimen is broken, the surface carbonization layer of the prescribed age is removed, adding the acetone or alcohol to store in the atmosphere of isolating the carbon dioxide. Grinding to make samples pass through the $4900 \mathrm{hole} / \mathrm{cm}^{2}$ standard sieve with agate mortar. In order to make the samples completely dehydrated, the acetone and alcohol added at least not less than two times. The hydrate dehydrated specimen, can be carried out by X ray diffraction analysis. Need to pay attention to grinding, when grinding each sample end need to use hydrochloric acid cleaning mortar before regrinding the next sample.

Scanning electron microscopy (SEM) analysis method was used to observe the morphology of the cement hydration product:

Take out of each age hydration of cement small fragments from acetone solution according to 
the different age, after in the drying oven for drying 2 hours in $70^{\circ} \mathrm{C}$, the small sample was vacuum sprayed with gold, the morphology of cement hydration products was observed by scanning electron microscopy (SEM).

\section{Test Results and Analysis}

1) Ordinary Portland cement was mixed in rapid hardening sulphoaluminate cement, rapid hardening sulphoaluminate cement mixture condensation time is shorter than the pure SAC or OPC when the dosage of $10 \% \sim 90 \%$ range, with the two kinds of cement ratio showing a regular change, the two cement each half setting time is the shortest[3]. The strength performance of blended cement is related to the mixing ratio of two cements. It was found that the initial test of the narrow interval when the ordinary cement in $25 \% \pm 5$ or so, the composite cementitious system still reflects the obvious early strength of hard and low shrinkage, the volume stability conforms to the new wall material product production technical requirements, the later performance improvement effect is quite good. Sulphoaluminate cement mixed with Portland cement, $\mathrm{C}_{4} \mathrm{~A}_{3}$ minerals in the SAC and $\mathrm{C}_{3} \mathrm{~S}$ minerals in the OPC promotes mutually in the process of co-hydration, the early hydration speed of mixed cement is accelerated and the hydration heat release is advanced, but the total amount of hydration heat in 48 hours decreases[4].

2) Our experiments show that: In the condition of Portland cement, physical and mechanical test results that the addition of silica fume was respectively $1 \%, 5 \%, 10 \%$ and the blank group, the flexural strength and compressive strength were compared with the blank group in the single factor experiment of silica fume. The amount of $5 \% 28 \mathrm{~d}$ strength increased relatively more, can solve a certain strength of the inverse problem, the compressive strength increases and the flexural strength increases obviously, the optimum amount of adding silica fume is $5 \%$, when the amount of silica fume increases to $10 \%$, the compressive strength and flexural strength decreases, and the shrinkage value increases obviously, this is consistent with the effect of silica fume on pure Portland cement. Sample 90d, 180d carbide coefficient and softening coefficient are higher, greater than or equal to $85 \%$. In the experiment of adding silica fume can be seen, it is helpful to solve the sulphoaluminate cement strength inverse, the later strength increases greatly, which indicates that carbonation powder phenomenon improves obviously. Analysis on the mechanism of silica fume: as silicon powder with small particle size, large specific surface area, so the cement paste and concrete mixes with silica fume, with increasing silicon powder dosage, the water demand increases, the self shrinkage increases.

In the condition of the portland cement existence, the influence mechanism of silica fume on hardening sulphoaluminate cement paste microstructure: (1)The hydration degree of cement is improved and the twice hydration reaction occurs with $\mathrm{Ca}(\mathrm{OH})_{2}$, increasing the number of the C-S-H gel in hardened cement paste, and improve the performance of traditional C-S-H gel, thus improve the performance of hardened cement paste. (2)The silicon powder and its twice hydration products filled with harmful pores in hardened cement paste, the macro pore and capillary porosity in cement paste decreases, at the same time gel holes and transition holes are added, the pore size distribution is greatly changed, the macropore is reduced, small holes are increased, and the distribution is even, thus changing the pore structure of hardened cement paste. (3)The incorporation of silica fume can consume $\mathrm{Ca}(\mathrm{OH})_{2}$ in cement slurry, and improve the interface performance of hardened cement paste and aggregate in concrete. After silica fume touching mixing water, first of all form rich silicon gel and absorb moisture; Gel aggregates between non hydrated cement particles, gradual encapsulates cement particles; $\mathrm{Ca}(\mathrm{OH})_{2}$ reacts with the surface of the rich silicon gel to produce C-S-H gel, these C-S-H gels are mostly generated in C-S-H gel pores of cement hydration, greatly improve the structural density. It is mainly due to the participation of silica fume, made high alkali compounds doped with Portland cement transform into low alkaline compounds later, at the same time creating the ettringite metastable condition, restraining shrinkage of cement paste compressive strength at later stage and improving the later performance index.

3) Effect of boric acid on sulphoaluminate cement: 
Adding borax or boric acid in rapid hardening sulphoaluminate cement, can play an obvious retarding effect. Pure rapid hardening sulphoaluminate cement hardening characteristics show the phenomenon of first expansion then contraction, this may be due to the rapid formation of early ettringite in rapid hardening sulphoaluminate cement hydration, due to the rapid gel speed, but its structure is not perfect, easy to transform into a single sulfur type $\mathrm{C}_{4} \mathrm{~A}_{3} \mathrm{~S}$, resulting in water evaporation causing drying shrinkage. The incorporation of retarders to slow sulphoaluminate cement coagulation can make the structure development and form more perfect, so it is beneficial to improve the later performance.

We do the confirmatory experiments of retarding effect show: When the content of $\mathrm{H} 3 \mathrm{BO} 3$ does not exceed $0.1 \%$, the retarding effect is not obvious; The initial setting time is only extended $20 \mathrm{~min}$, and the final setting time is only extended $10 \mathrm{~min}$; Once the content of $\mathrm{H} 3 \mathrm{BO} 3$ increases to $0.3 \%$, the cement setting time is sharply prolonged, the initial setting time and final setting time are $510 \mathrm{~min}$ and $597 \mathrm{~min}$ longer than the blank sample respectively. The retarding mechanism is that when $\mathrm{H} 3 \mathrm{BO} 3$ is added to the sulphoaluminate cement, the cement suspension becomes stable due to the formation of the calcium borate coating on the surface of the cement particles hydration layer, and the cement particles are prevented from coagulating, so the condensation of cement can be delayed. When the content of $\mathrm{H} 3 \mathrm{BO} 3$ is lesser, calcium borate can not completely wrap cement clinker particles, the cement clinker will quickly hydrate in areas not wrapped; And water and SO42-, etc. can also be infiltrated from the unencapsulated into the wrapping film, the wrapped area of the membrane is also hydrated, the volume expansion during the formation of ettringite leads to the coating film wrap off gradually, thus slightly delaying the condensation of sulphoaluminate cement. When the dosage of $\mathrm{H} 3 \mathrm{BO} 3$ is larger, the generated calcium borate the coating film of formation is too thick and dense, the water molecules through the film into the membrane are very difficult in all parts, resulting in cement for a long time without condensation. The incorporation of $\mathrm{H} 3 \mathrm{BO} 3$ in sulphoaluminate cement, cement paste $4 \mathrm{~h}$ and $6 \mathrm{~h}$ compressive strength decreases with the increase of its content; The $1 \mathrm{~d}$ compressive strength increases when the content is less than $0.1 \%$. When the dosage is more than $0.1 \%$, the compressive strength decreases with the increase of $\mathrm{H} 3 \mathrm{BO} 3$ content; The compressive strength of cement paste with $0.2 \%$ and $0.3 \%$ increases by more than $10 \mathrm{MPa}$ compared with the blank sample and the cement paste with the addition of $0.1 \%$ $\mathrm{H} 3 \mathrm{BO} 3$. It can be seen that the addition of $\mathrm{H} 3 \mathrm{BO} 3$ will reduce the early strength of sulphoaluminate cement, but the appropriate amount of $\mathrm{H} 3 \mathrm{BO} 3$ can improve the later strength of cement.

4) Hydration product and mechanism analysis

According to the domestic scholars correlative analysis, and our preliminary study on the hydration mechanism of fast-hardening sulphoaluminate cement and ordinary Portland cement or silica fume composite gel material shows that: the results of experimental analysis by XRD and SEM show that the hydration products of the composite cementitious material mortar specimen prepared with different ratios are all the same, the type of forming hydration products that sulphoaluminate cement and ordinary Portland cement mixed with silica fume is basically the same, only in the hydration product quantity has changed. The combination of two kinds cement and silica fume can accelerate the hydration process of composite cementitious material system, composite cement gelled material system general process of hydration is as follows:

Firstly:

$$
\begin{aligned}
& \mathrm{C}_{4} \mathrm{~A}_{3} \mathrm{~S}+2 \mathrm{CSH}_{2}+36 \mathrm{H}=\mathrm{C}_{3} \mathrm{~A} \cdot 3 \mathrm{CS} \cdot \mathrm{H}_{32}+2 \mathrm{~A} \mathrm{H}_{3}(\text { gel }) \\
& \mathrm{C} 3 \mathrm{~A}+\mathrm{CH}+12 \mathrm{H}=\mathrm{C} 4 \mathrm{~A} \cdot \mathrm{H} 13 \\
& \mathrm{C} 3 \mathrm{~S}+3 \mathrm{H}=\mathrm{C}-\mathrm{S}-\mathrm{H}(\text { gel })+2 \mathrm{CH}
\end{aligned}
$$

In the presence of gypsum, especially in the $\mathrm{Ca}(\mathrm{OH}) 2$ solution, the following reactions take place between the hydrated products: 


$$
\mathrm{A} \mathrm{H} 3(\text { gel })+3 \mathrm{CH}+3 \mathrm{CSH} 2+20 \mathrm{H}=\mathrm{C} 3 \mathrm{~A} \cdot 3 \mathrm{CS} \cdot \mathrm{H} 32
$$

As the hydration reaction proceeds, the $\mathrm{C}_{3} \mathrm{~S}$ and $\mathrm{C}_{2} \mathrm{~S}$ in the cementite reacts with water to form $\mathrm{C}-\mathrm{S}-\mathrm{H}$ gel and $\mathrm{CH}$ crystal, the $\mathrm{CH}$ content in the cement stone increases with the occurrence of the reaction, and the formed ettringite has swelling property in the sufficient amount of $\mathrm{CH}$. After the SAC and OPC composite, the setting time of the composite cement is not the superposition of the coagulation time when the cement is hydrated separately. except for the combination ratio of $90 \%$ OPC and $10 \%$ SAC, the coagulation time of other mixed samples are shorter than that of SAC or OPC, some mixed proportions even reach the quick-setting. From the hydration heat test results, it can be seen that the combination of SAC and OPC does accelerate the hydration of composite cement, making the heat release in advance. With SAC as the main, OPC is incorporated into SAC, due to the alkalinity increase of composite cement paste, $\mathrm{C}_{4} \mathrm{~A}_{3}$ hydration speeds up, and the $\mathrm{CH}$ formed by the hydration of $\mathrm{C}_{3} \mathrm{~S}$ in the OPC (reaction formula 3 ) is involved in the reaction in which the aluminum gel is converted to ettringite (reaction formula 4), this also promotes the hydration of $\mathrm{C}_{4} \mathrm{~A}_{3}$ (reaction 1), leading to an increase in the amount of ettringite and aluminum gel formation and a rapid acceleration of the condensation in the cement paste. In fact, the consumption of $\mathrm{CH}$ also promotes the acceleration of $\mathrm{C}_{3} \mathrm{~S}$ and $\mathrm{C}_{2} \mathrm{~S}$ hydration, so $\mathrm{C}_{4} \mathrm{~A}_{3}$ and $\mathrm{C}_{3} \mathrm{~S}$ minerals are mutually promoted in the initial hydration, and the combination of SAC and OPC plays a role in mutual promotion of hydration. If it is given priority to OPC, SAC is incorporated into OPC, due to increase the content of hydrated minerals $\mathrm{C}_{4} \mathrm{~A}_{3}$ soon, the formation rate of ettringite and aluminium gel accelerates, and consumes $\mathrm{CH}$, reducing the alkalinity of the cement slurry, promoting the hydration of $\mathrm{C}_{3} \mathrm{~S}$, also leading to the acceleration of condensation rate. We believe that these analyses are consistent with the experimental results.

The results of electron microscope test 1 samples (SAC:OPC:SI:water $=200: 50: 100: 175$ ) in our previous study trial were performed for 90 days show that: internal hydration product morphology description and energy spectrum analysis.

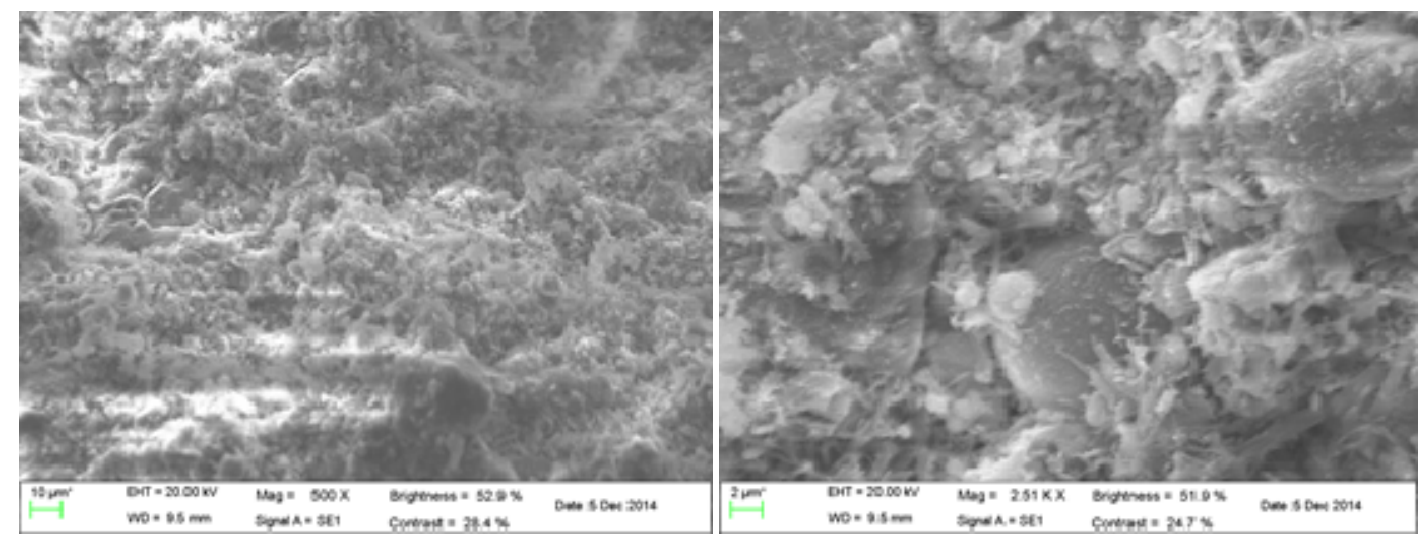

$\mathrm{CH}$ : piece of plate; AFt: short thick needle rod; C-S-H: cloud flocculent glue.

Fig 1. Micro electron microscope analysis 


\begin{tabular}{c|cc}
\hline $\begin{array}{c}\text { eleme } \\
\text { nt }\end{array}$ & Weight & Atomic \\
& $\begin{array}{c}\text { percentag } \\
\text { e }\end{array}$ & $\begin{array}{c}\text { percent } \\
\text { age }\end{array}$ \\
$\mathrm{C} \mathrm{K}$ & 9.30 & 13.59 \\
$\mathrm{O} \mathrm{K}$ & 65.40 & 71.72 \\
$\mathrm{Na} \mathrm{K}$ & 0.53 & 0.40 \\
$\mathrm{Al} \mathrm{K}$ & 8.93 & 5.81 \\
$\mathrm{Si} \mathrm{K}$ & 7.85 & 4.90 \\
$\mathrm{~S} \mathrm{~K}$ & 1.54 & 0.85 \\
$\mathrm{~K} \mathrm{~K}$ & 0.55 & 0.25 \\
$\mathrm{Ca} \mathrm{K}$ & 5.02 & 2.20 \\
$\mathrm{Ti} \mathrm{K}$ & 0.27 & 0.10 \\
Fe K & 0.61 & 0.19 \\
total & 100.00 & \\
\hline
\end{tabular}

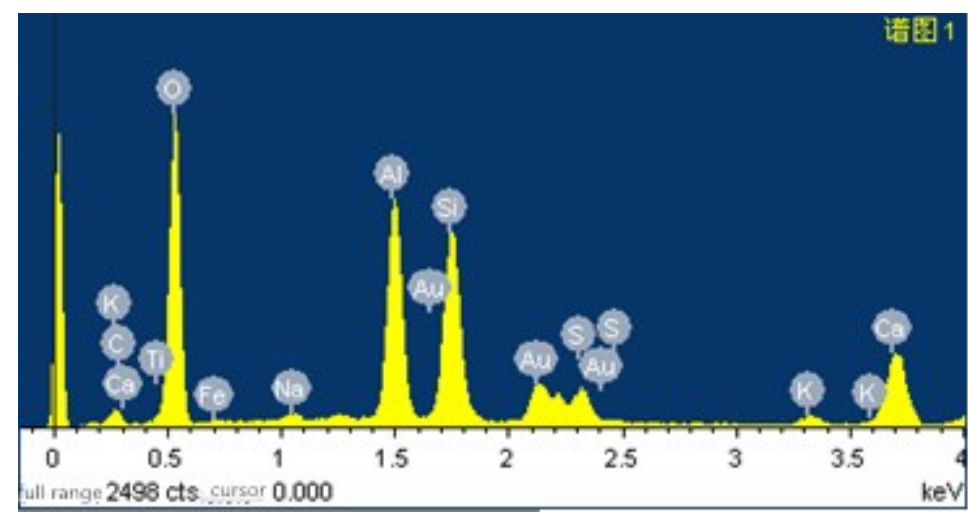

Fig 2. Energy spectrum analysis

\section{Conclusions}

The main hydration products of rapid hardening sulphoaluminate and Portland cement add silica fume composite cementitious material system are ettringite, aluminum hydroxide gel, C-S-H gel and single sulfur hydrated sulphoaluminate. Due to the retarding effect of boric acid after the dissolution of $\mathrm{SO}_{4}{ }^{2-}$, and with tetra-calcium sulphoaluminate or aluminum hydroxide gel reacts to form ettringite, more importantly, due to the participation of silica fume, later to make the formed high alkali compounds doped with Portland cement into low alkaline compounds, filling the pore of cement stone. The ettringite and aluminum hydroxide gel, the C-S-H gel are overlapped each other, and the structure is dense. At the same time, the ettringite metastable condition is established, which inhibits cement stone fall of late compressive strength.

\section{References}

[1] Wang Yanmou, Su Muzhen, Zhang Liangzhong. The Classification of Sulphoaluminate Cement and the Difference between Its Varieties[J], China Cement, 2007, 2.

[2] Wang Hongzhen, Yang Junxiao. Experimental Study on Flowing Lightweight Aggregate Microporous Concrete[J], Journal of Building Materials, Vol. 14, No. 2, April 2011.

[3] Wang Fusheng, Yang Haiyan, Tang Shifa. Effect of Sulphoaluminate Cement Mixed with Portland Cement on Properties of Composite Cement[J]. Beijing Building Materials, 1996 , (2) :1722.

[4] Chen Juan, The Performance Adjustment and Applied Research of Sulphoaluminate Cement[D]. Wuhan: Wuhan University, 2005. 